\title{
Role of Isosorbide Mononitrate as an Agent for Cervical Ripening in Second-trimester Abortions
}

\author{
Anupama Dave ${ }^{1}$, Pushplata Mourya ${ }^{2}$, Atisha Dave ${ }^{3}$
}

\begin{abstract}
Objective: To compare the effectiveness and safety of isosorbide mononitrate (IMN), misoprostol (MP), and mechanical dilatation (MD) for cervical ripening in second-trimester abortions.

Methodology: The present study was conducted in the Department of Obstetrics and Gynaecology, MGM Medical College, Indore, Madhya Pradesh, from September 2014 to August 2015. One-hundred and fifty women who had a valid indication for termination were included after informed consent and randomized into three groups of 50 each. Women with hypotension BP $8 \mathrm{~mm}$ were excluded.

Results: In the study, indications for termination were fetal conditions (14.6\%), maternal conditions (19.3\%), contraceptive failure (39.3\%), IUFD $(16.6 \%)$, and others (10\%). The mean \pm SD of Bishop score before and after IMN were $1.18 \pm 1.43$ and $4.54 \pm 1.70$, whereas for MP, $1.2 \pm 1.525$ and $4.76 \pm 1.80$, and for MD, $1.3 \pm 1.46$ and $4.36 \pm 1.56$, respectively ( $p=0.000$ significant). The mean \pm SD of induction ripening interval of $10.9 \pm 3.23,9.76 \pm 3.17$, and $12.92 \pm 2.65$ for IMN, MP, and MD $(p=0.000)$ shows that it was least for MP followed by IMN and MD. Comparison of induction-abortion interval showed mean \pm SD of $28.32 \pm 9.84,29.00 \pm 7.22$, and 38.76 \pm 9.87 for IMN, MP, and MD, respectively $(p=0.000)$. All cases of IMN and MP aborted vaginally; in MD group, $4 \%$ had a hysterotomy. Side effects were minimal in IMN group with only headache which was tolerable.

Conclusion: IMN when compared with MP and MD proved to be a good cervical ripening agent for second-trimester abortions. It is safe, effective, and has minimum side effects. More studies are required for establishment of IMN as a ripening agent.

Keywords: Cervical ripening, Second-trimester termination of pregnancy, Vaginal isosorbide mononitrate.

Journal of South Asian Federation of Obstetrics and Gynaecology (2021): 10.5005/jp-journals-10006-1961
\end{abstract}

\section{INTRODUCTION}

Abortion is the ending of pregnancy by removing a fetus or embryo from the womb before it can survive on its own. Induction of abortion is one of the commonly practiced interventions in modern obstetrics; for induction, cervical ripening is very important, and to prevent complications, the cervix may be slowly opened after ripening (softening) with a cervical ripening agent.

Induction of cervical ripening and labor remains one of the therapeutic challenges in the field of obstetrics. When the fetus has to be delivered preterm due to maternal or fetal complications, the cervix is usually very rigid and unripe; it is therefore of vital importance to coordinate the onset of labor with adequate cervical ripening. ${ }^{1}$

Various methods have been tried to shorten the inductionabortion interval and therefore lessen the cumulative amount of prostaglandins needed which are the commonest agents used for both cervical ripening and abortion. Mifepristone is effective, but it is not cost-effective and prolongs the induction-abortion interval. An alternative is to insert an intracervical laminaria tent 12 hours before induction. ${ }^{2,3}$ However, this is less effective than mifepristone. Other agents which are now commonly used are misoprostol, mechanical dilatation, and nitric oxide donor isosorbide mononitrate (IMN). The insertion of a Foley catheter into the cervical canal is one of the more commonly used mechanical methods. The technique is more cost-effective compared with other mechanical methods. ${ }^{4,5}$

Nitric oxide is a free radical with a very short half-life. The nitricoxide-generating system has been shown to exist in the human female genital tract, and there is an upregulation of the system

\begin{abstract}
${ }^{1,2}$ Department of Obstetrics and Gynaecology, Mahatma Gandhi Memorial Medical College, Indore, Madhya Pradesh, India

${ }^{3}$ Sri Aurobindo Institute of Medical Sciences, Indore, Madhya Pradesh,
\end{abstract} India

Corresponding Author: Anupama Dave, Department of Obstetrics and Gynaecology, Mahatma Gandhi Memorial Medical College, Indore, Madhya Pradesh, India, e-mail: anupamadave10@gmail.com

How to cite this article: Dave A, Mourya P, Dave A. Role of Isosorbide Mononitrate as an Agent for Cervical Ripening in Second-trimester Abortions. J South Asian Feder Obst Gynae 2021;13(5):319-323.

Source of support: Nil

Conflict of interest: None

with advanced gestation. ${ }^{6}$ The nitric oxide donors have been tested in various clinical applications, including cervical ripening, during first-trimester pregnancy and third-trimester pregnancy. ${ }^{7,8}$ There are only a few studies on its use in the second trimester. ${ }^{9}$ Previous studies used a lesser total dose and combinations with misoprostol, and did not show any additional benefit. ${ }^{10}$ IMN if repeated as the second dose used in higher dose or dinitrate gel preparation will have better results without side effects which are common with prostaglandins. ${ }^{11}$ A study done for the use of IMN for cervical ripening in term pregnancies also had good results. ${ }^{12}$

Given the effectiveness of nitric oxide donor IMN in causing cervical ripening, a prospective randomized and double-blinded clinical trial was therefore conducted to investigate its efficacy in improving cervical ripening and induction-abortion interval in second-trimester abortions.

() The Author(s). 2021 Open Access This article is distributed under the terms of the Creative Commons Attribution 4.0 International License (https://creativecommons. org/licenses/by-nc/4.0/), which permits unrestricted use, distribution, and non-commercial reproduction in any medium, provided you give appropriate credit to the original author(s) and the source, provide a link to the Creative Commons license, and indicate if changes were made. The Creative Commons Public Domain Dedication waiver (http://creativecommons.org/publicdomain/zero/1.0/) applies to the data made available in this article, unless otherwise stated. 


\section{Materials and Methods}

The present study was conducted in the Department of Obstetrics and Gynaecology, MGM Medical College, and MY Hospital, Indore, Madhya Pradesh, from September 2014 to August 2015.

\section{Study Design}

One-hundred and fifty women who had a valid indication for termination were included in the study after informed consent and randomized into three groups of 50 each:

- Group I (IMN): In this group, patients were given $40 \mathrm{mg}$ IMN vaginally, and dose was repeated after 6 hours only two doses were given.

- Group II (MP): $400 \mu \mathrm{g}$ of misoprostol was placed in the posterior vaginal fornix, and repeated after 4 hours two doses were given for ripening of the cervix.

- Group III (MD): In this group, intracervical Foley catheter was placed extra-amitotically filled with 30 cc normal saline and traction given this helps in the release of prostaglandins and cervical ripening. Cervix was assessed after 12 hours or till Foleys came out whichever earlier.

\section{Inclusion Criteria}

- Intrauterine pregnancy of the second trimester.

- Patients who are capable of giving the consent and sign the form.

- Abortion is being made in compliance with the Abortion Act 1971.

\section{Exclusion Criteria}

- Hypotension BP $<100 / 60$

- H/o headache, alcohol abuse

- Allergy or hypersensitivity to nitrates

- Previous uterine scar

\section{Methodology}

After proper counseling and consent, patients were allotted in the three groups and given the respective drugs. The double-blinded technique was applied to decrease observer bias and patient bias. General examination was done, maternal blood pressure and pulse rate assessed at regular intervals, complete obstetric examination and preliminary laboratory investigations were done, and subsequent monitoring was done of progression to cervical ripening and abortion.

During this procedure, vital signs, symptoms, and adverse effects were recorded at baseline and then at regular intervals until finishing therapy. Time and dose of tablet given and Foleys inserted were noted, and induction-ripening interval was recorded. Once cervical ripening occurred, all women were given misoprostol for abortion.

\section{Statistical Analysis}

Data were analyzed by using the ANOVA test to compare between the three groups. $p<0.05$ was considered significant. Mean and standard deviation of Bishop score before and after were analyzed by Wilcoxon signed rank test.

\section{Results}

In the study, main observations are as follows:

Indications for termination were fetal conditions (14.6\%), maternal conditions (19.3\%), contraceptive failure (39.3\%), IUFD (16.6\%), and others (10\%).
The mean \pm SD of Bishop score before and after IMN, MP, and MD are $1.18 \pm 1.43$ and $4.54 \pm 1.70,1.2 \pm 1.525$ and $4.76 \pm 1.80$ and $1.3 \pm 1.46$ and $4.36 \pm 1.56$, respectively ( $p=0.000$ significant).

The mean \pm SD of induction ripening interval for IMN, MP, and MD are $10.9 \pm 3.23,9.76 \pm 3.17$, and $12.92 \pm 2.65$, respectively $(p=0.000)$, which shows that it was least for MP followed by IMN and MD.

Comparison of induction-abortion interval showed mean \pm SD for IMN (28.32 \pm 9.84$)$, MP $(29.00 \pm 7.22)$, and MD (38.76 \pm 9.87$)$, respectively $(p=0.000)$.

All cases of IMN and MP aborted vaginally; in the MD group, $4 \%$ had a hysterotomy.

Side effects were minimal in the IMN group with only tolerable headache.

\section{Discussion}

In the present study, IMN was comparatively studied with MP and MD for cervical ripening in second-trimester abortions. Onehundred and fifty cases were enrolled in this study and divided into three groups, IMN, MP, and MD containing 50 each. The primary outcomes measured were changes in the Bishop score and induction-abortion interval.

If we look at the demographic profile of the women included in the study, the mean age was 23.6 years, $35.3 \%$ were primigravidas, and $64.6 \%$ multigravidas, and the majority had a gestational age between 12 and 15 weeks (92/150). The majority of women belonged to the lower class and were illiterate or educated up to the primary. Baseline demographic characteristics were similar in all groups (Table 1).

As per MTP Act and Law in certain conditions, only termination of pregnancy up to 20 weeks is possible with the consent of two registered medical practitioners/consultants. In our study, indications for abortions were for fetal conditions (congenital anomalies) (14.6\%), maternal conditions (preeclampsia, eclampsia, diabetes, cardiac) (19.3\%), contraceptive failure (39.3\%), IUFD (16.6\%), and others (10\%)

Table 1: Demographic variables

\begin{tabular}{lcc}
\hline Variable & Frequency & Mean \pm SD \\
\hline Age & & $23.61 \pm 3.47$ \\
Gestational age (week) & & \\
$12-15$ & 92 \\
$16-18$ & 45 \\
$19-20$ & 13 \\
Total & 150 \\
Parity primi & $53(35.33 \%)$ \\
Multi & $97(64.66 \%)$ \\
Total & $150(100 \%)$ \\
Socioeconomic status & \\
Upper middle class & 10 \\
Lower middle class & 20 \\
Upper lower class & 40 \\
Lower class & 80 \\
Total & 150 \\
Education & \\
High school & 10 \\
Middle school & 30 \\
Primary education/literate & 50 \\
Illiterate & 60 \\
Total & 150 \\
\hline
\end{tabular}


(Table 2). It is seen that in these conditions in the second trimester, the cervix is rigid and in some prostaglandins may be contraindicated in certain medical conditions, so other methods for cervical ripening, like MD and IMN, will then be beneficial.

Significant changes in the Bishop score were found in the three groups-it was due to the particular regime which was followed for cervical ripening. The mean \pm SD of Bishop score before and after IMN was $1.18 \pm 1.43$ and $4.54 \pm 1.70$, for MP was $1.2 \pm 1.525$ and $4.76 \pm 1.80$, and for MD was $1.3 \pm 1.46$ and $4.36 \pm 1.56(p=0.000)$ which is significant. The maximum change in the Bishop score was achieved by MP followed by IMN and then by MD. Rameez et al. $^{13}$ in a study found favorable effects with IMN in cervical ripening, but it was studied in cases of term pregnancy. They used a dose of $60 \mathrm{mg}$ IMN which is similar to our study, so using IMN in second-trimester pregnancy also has similar effects in cervical ripening (Table 3 ).

In the present study, use of $40 \mathrm{mg}$ IMN twice at 6-hour interval was found to be effective and comparable to MP, the study induction-ripening interval was analyzed, and in the present study, results showed that the mean \pm SD of induction-ripening interval for IMN was $10.9 \pm 3.23$, while that for MP was $9.76 \pm 3.17$ and for MD was mean \pm SD $12.92 \pm 2.65$ ( $p=0.000$ was significant in all the three groups). The results show that the induction-ripening interval was maximum for MD followed by IMN and then MP; it makes MP as a best cervical ripening agent among the three. Shafique et al. ${ }^{14}$ in their study on first-trimester preoperative cervical ripening found that the mean induction to ripening interval was significantly higher in the IMN group as compared with the misoprostol group

Table 2: Indication for termination of pregnancy

\begin{tabular}{lcc}
\hline Indication & Frequency & $\%$ \\
\hline Fetal conditions requiring termination & 22 & 14.66 \\
(congenital anomalies) & 12 & \\
1. Anencephaly & 2 & \\
2. Hydrops fetalis & 1 & \\
3. Spina bifida & 3 & \\
4. Meningomyelocoele & 4 & \\
5. Major hydrocephalus & 29 & 19.33 \\
Maternal conditions requiring termination & 11 & \\
1. Preeclampsia & 7 & \\
2. Eclampsia & 5 & \\
3. Uncontrolled DM & 2 & \\
4. Cardiac disease (Grades 3 and 4) & 4 & \\
5. Uncontrolled epilepsy & 59 & 39.33 \\
Contraception failure & 25 & 16.66 \\
Intrauterine fetal demise & 15 & 10 \\
Others & 11 & \\
1. Socioeconomic condition & 4 & \\
2. Sexual assault & & \\
\hline
\end{tabular}

$(8.032 \pm 2.833$ vs $4.47 \pm 2.042, p<0.05)$. No such studies on induction and ripening interval have been reported in second-trimester pregnancies.

Induction-abortion interval is the main determinant of the effectiveness of any agent used for ripening, and a less interval is favorable as it decreases the hospital stay and enhances patient satisfaction. For the three groups in our study, the results showed that the mean induction-abortion interval for IMN was $28.32 \pm 9.84$, for MP was $29.00 \pm 7.225$, and for MD was $38.76 \pm 9.87(p=0.000$ which is significant). It was least for IMN followed by MP and maximum for MD. The comparison was also done between the three groups which show that there is a significant difference/ $p$-value is significant between IMN and MD and between MP and MD, while it is nonsignificant between IMN and MP (Table 4).

In a study by Mousiolis et al., ${ }^{15}$ the mean induction to complete abortion interval was 20.4 hours [95\% confidence interval $(\mathrm{Cl})=16.63-24.17]$ in the misoprostol group compared with 12.4 hours (95\% Cl $=10.33-14.47)$ in the misoprostol plus IMN group; thus, shortening effect of the IMN was statistically significant.

In the IMN group, 100\% aborted vaginally, in the MP group also, $100 \%$ aborted vaginally, while in the MD group, $4 \%$ required a hysterotomy (Table 5). This seems to be the major advantage of IMN over the other agents.

Prostaglandins are known to be associated with GI side effects. On analysis of side effects in the three groups, it was seen that headache was the main side effect with IMN which was absent in the other two groups; out of 50 women who received IMN, 8 women experienced headache (16\%). In the other two groups, MP and MD's main side effects were fever, nausea, vomiting, abdominal pain, and vaginal bleeding. Shafique et al. ${ }^{14}$ also found similar results (Table 6).

Headache was significantly high in the IMN group than in the MP group ( $p=0.05$ ). There was no significant difference in hypotension in both groups ( $p>0.005)$, abdominal pain was significantly higher in the MP group as compared to the IMN group $(p<0.05)$, and the backache was the same in both groups $(p>0.05)$. Nausea and vomiting observed in the MP group $(p<0.05)$ were significantly higher as compared to the IMN group. In the PRIM study by Osman et al., ${ }^{16}$ in which PGE2 and IMN were compared for cervical ripening before induction of term labor, it was concluded that the safety profile of IMN was such that it can be given on an outpatient basis.

IMN seems to be an effective and safe cervical ripening agent, having no significant side effects except headache which is tolerable and of mild intensity. This is comparable with our study in which a similar dose of IMN was used but in term pregnancies for cervical ripening. ${ }^{17}$

According to a recent study by Sivakumar et al., ${ }^{18}$ vaginally administered IMN seems to be a safe and effective method in second-trimester pregnancy termination. There is a reduction in

Table 3: Bishop's score before and after induction

\begin{tabular}{|c|c|c|c|c|c|c|c|c|c|c|c|c|}
\hline \multirow[b]{3}{*}{ Bishop's score } & \multicolumn{6}{|c|}{ Before induction } & \multicolumn{6}{|c|}{ After induction } \\
\hline & \multicolumn{2}{|c|}{ IMN } & \multicolumn{2}{|c|}{$M P$} & \multicolumn{2}{|c|}{$M D$} & \multicolumn{2}{|c|}{$I M N$} & \multicolumn{2}{|c|}{$M P$} & \multicolumn{2}{|c|}{$M D$} \\
\hline & $N$ & $\%$ & $N$ & $\%$ & $N$ & $\%$ & $N$ & $\%$ & $N$ & $\%$ & $N$ & $\%$ \\
\hline 0 & 27 & 54 & 29 & 58 & 23 & 46 & 19 & 38 & 15 & 30 & 23 & 46 \\
\hline $1-2$ & 15 & 30 & 11 & 22 & 19 & 38 & 23 & 46 & 27 & 54 & 21 & 42 \\
\hline $3-4$ & 8 & 16 & 10 & 20 & 8 & 16 & 7 & 14 & 5 & 10 & 6 & 12 \\
\hline 9-10 & - & - & - & - & - & - & 1 & 2 & 3 & 6 & 0 & 0 \\
\hline Mean \pm SD & \multicolumn{2}{|c|}{$1.18 \pm 1.453$} & \multicolumn{2}{|c|}{$1.2 \pm 1.525$} & \multicolumn{2}{|c|}{$1.3 \pm 1.46$} & \multicolumn{2}{|c|}{$4.54 \pm 1.705$} & \multicolumn{2}{|c|}{$4.76 \pm 1.80$} & \multicolumn{2}{|c|}{$4.36 \pm 1.56$} \\
\hline
\end{tabular}


Table 4: Induction ripening interval

\begin{tabular}{lrrrrrrrrr}
\hline & \multicolumn{2}{c}{$I M N$} & & \multicolumn{2}{c}{$M P$} & & \multicolumn{2}{c}{$M D$} \\
\cline { 2 - 3 } \cline { 8 - 9 } Time (in hours) & $N$ & $\%$ & & $N$ & $\%$ & & $N$ & $\%$ \\
\hline 6 & 13 & 26 & & 20 & 40 & & 4 & 8 \\
12 & 29 & 58 & & 27 & 54 & & 22 & 44 \\
$>12$ & 8 & 16 & & 3 & 6 & & 24 & 48 \\
Total & 50 & 100 & & 50 & 100 & & 50 & 100 \\
Mean \pm SD & $10.9 \pm 3.23$ & & $9.76 \pm 3.17$ & & $12.92 \pm 2.65$ \\
\hline
\end{tabular}

Table 5: Induction-abortion interval and mode of abortion

\begin{tabular}{lcccccccc}
\hline & \multicolumn{3}{c}{$I M N$} & & \multicolumn{2}{c}{$M P$} & & \multicolumn{3}{c}{$M D$} \\
\cline { 2 - 3 } \cline { 8 - 9 } Time (in hours) & $N$ & $\%$ & & $N$ & $\%$ & & $N$ & $\%$ \\
\hline $12-24$ & 17 & 34 & & 20 & 40 & & 7 & 14 \\
$25-36$ & 25 & 50 & & 25 & 50 & & 12 & 24 \\
$37-48$ & 6 & 12 & & 3 & 5.76 & & 19 & 38 \\
$>48$ & 2 & 4 & & 2 & 4 & & 12 & 24 \\
Mean \pm SD & $28.32 \pm 9.84$ & & $29.00 \pm 7.22$ & & $38.76 \pm 9.87$ \\
Abortion vaginal & 50 & 100 & & 50 & 100 & & 48 & 96 \\
Hysterotomy & 0 & - & & 0 & - & & 2 & 4 \\
Total & 50 & 100 & & 50 & 100 & & 50 & 100 \\
\hline
\end{tabular}

Table 6: Maternal side effects

\begin{tabular}{|c|c|c|c|c|c|c|}
\hline \multirow{2}{*}{$\begin{array}{l}\text { Side effects and adverse } \\
\text { effects }\end{array}$} & \multicolumn{2}{|c|}{$I M N$} & \multicolumn{2}{|c|}{$M P$} & \multicolumn{2}{|c|}{$M D$} \\
\hline & $N$ & $\%$ & $N$ & $\%$ & $N$ & $\%$ \\
\hline Headache & 8 & 16 & - & - & - & - \\
\hline Hypotension & 1 & 2 & - & - & - & - \\
\hline Fever & - & - & 6 & 12 & 9 & 18 \\
\hline Nausea and vomiting & 1 & 2 & 4 & 8 & 3 & 6 \\
\hline $\begin{array}{l}\text { Abdominal pain and vaginal } \\
\text { bleeding }\end{array}$ & - & - & 29 & 58 & 23 & 46 \\
\hline
\end{tabular}

hospital stay, manpower, economy spent on the patient, and a sense of well-being from the patient also. According to our study too, IMN if given in a dose $40 \mathrm{mg}$ vaginally 6 hours apart was effective in cervical ripening and with minimal side effects.

On the contrary, a recent study by Dixi et al. ${ }^{19}$ concluded that the drug-related side effects are more in the IMN group as compared with the PGE2 group. But, we must not forget that the main advantage of IMN could be that it can easily be used in those who have contraindications to prostaglandins.

Some studies mention the importance of surgical methods over medical methods in second-trimester abortions as in the study by Chhetri et al. ${ }^{20}$ In all such cases, perhaps cervical ripening is the prime factor responsible for better outcomes, and the side effects which may occur due to medications that are being used still could be considered in a few cases. Thereby, it may be emphasized that we need to adopt an individualized approach for all such cases considering the pros and cons of the various methods.

\section{CONCLUSION}

Based on the present study, it can be said that for second-trimester abortions, cervical ripening plays an important role. IMN when compared with MP and MD proved to be a good cervical ripening agent with minimal maternal side effects, and the only major side effect was a headache, which was of mild intensity and well tolerable. Overall, misoprostol was the best ripening agent followed by IMN then MD, but induction-abortion interval was least for IMN followed by MP and maximum for MD, so induction-abortion interval can be reduced due to pre-induction ripening with IMN; due to this, hospital stay and associated morbidity can be reduced ultimately enhancing patient satisfaction.

\section{Clinical Significance}

Although more studies are required for the establishment of IMN as a ripening agent, cervical ripening effects of nitric oxide donors may still have a role in clinical practice in women for whom prostaglandins are contraindicated; for example, asthmatics with severe bronchospasm or women with known hypersensitivity to prostaglandins can be used safely in other comorbid conditions, and if combined with prostaglandins, a lower dose of both may reduce the cost and prevent their side effects. However, more studies are required for the use of IMN in second-trimester abortions, to prove its efficacy for routine use.

\section{References}

1. Word RA, Li XH, Hnat M, et al. Dynamics of cervical remodeling during pregnancy and parturition: mechanisms and current concepts. Semin Reprod Med 2007;25(1):69-79. DOI: 10.1055/s-2006-956777. Available from: https://pubmed.ncbi.nlm.nih.gov/17205425/.

2. Ho PC, Tsang SS, Ma HK. Reducing the induction to abortion interval in termination of second-trimester pregnancies: a comparison of mifepristone with laminaria tent. Br J Obstet Gynecol 1995;102(8): 648-651. DOI: 10.1111/j.1471-0528.1995.tb11404.x. Available from: https://pubmed.ncbi.nlm.nih.gov/7654644/.

3. Maradny EE, Kanayama N, Halim A, et al. Biochemical changes in the cervical mucus after application of laminaria tent. Acta Obstet Gynecol Scand 1996;75(3):203-207.DOI: 10.3109/00016349609047087. Available from: https://pubmed.ncbi.nlm.nih.gov/8607329/.

4. Lim CED, Ng RWC, Xu K. Non-hormonal methods for induction of labour. Curr Opin Obstet Gynecol 2013;25(6):441-447. DOI: 10.1097/ GCO.0000000000000027. Available from: https://pubmed.ncbi.nlm. nih.gov/24121598/.

5. Chen W, Xue J, Peprah MK, et al. A systematic review and network meta-analysis comparing the use of Foley catheters, misoprostol, and dinoprostone for cervical ripening in the induction of labour. BJOG 2016;123(3):346-354. DOI: 10.1111/1471-0528.13456.

6. Ekerhovd E, Brännström M, Weijdegård B, et al. Nitric oxide synthases in the human cervix at term pregnancy and effects of nitric oxide on cervical smooth muscle contractility. Am J Obstet Gynecol 2000;183(3):610-616. DOI: 10.1067/mob.2000.105901.

7. Romero R. Clinical application of nitric oxide donors and blockers. Human Reprod [Oxford, England] 1998;13(2):248-250. DOI: 10.1093/ humrep/13.2.248. Available from: https://pubmed.ncbi.nlm.nih.gov/ 9557813/.

8. Thomson AJ, Lunan CB, Cameron AD, et al. Nitric oxide donors induce ripening of the human uterine cervix: a randomised controlled trial. $\mathrm{Br} J$ Obstet Gynaecol 1997;104(9):1054-1057.DOI: 10.1111/j.1471-0528.1997. tb12066.x. Available from: https://pubmed.ncbi.nlm.nih.gov/ 9307534/.

9. $\mathrm{LiCFI}$, Chan CWC, Ho PC. A study of the efficacy of cervical ripening with nitric oxide donor versus placebo for cervical priming before second-trimester termination of pregnancy. Contraception 2003;68(4):269-272. DOI: 10.1016/s0010-7824(03)00170-7. Available from: https://pubmed.ncbi.nlm.nih.gov/14572890/.

10. Ledingham MA, Thomson AJ, Lunan CB, et al. A comparison of isosorbide mononitrate, misoprostol and combination therapy for first trimester pre-operative cervical ripening: a randomised controlled trial. BJOG 2001;108(3):276-280. DOI: 10.1111/j.14710528.2001.00041.x. Available from: https://pubmed.ncbi.nlm.nih.gov/ $11281468 /$. 
11. Arteaga-Troncoso G, Villegas-Alvarado A, Belmont-Gomez A, et al. Intracervical application of the nitric oxide donor isosorbide dinitrate for induction of cervical ripening: a randomised controlled trial to determine clinical efficacy and safety prior to first trimester surgical evacuation of retained products of conception. BJOG 2005;112(12):1615-1619. DOI: 10.1111/j.14710528.2005.00760.x. Available from: https://pubmed.ncbi.nIm. nih.gov/16305563/.

12. Ekerhovd $\mathrm{E}$, Bullarbo $\mathrm{M}$, Andersch B. Vaginal administration of the nitric oxide donor isosorbide mononitrate for cervical ripening at term: a randomized controlled study. Am J Obstet Gynecol 2003;189(6):1692-1697. DOI: 10.1016/s0002-9378(03)00865-2. Available from: https://pubmed.ncbi.nlm.nih.gov/14710100/.

13. Rameez MFM, Goonewardene IMR. Nitric oxide donor isosorbide mononitrate for pre-induction cervical ripening at 41 weeks' gestation: a randomized controlled trial. J Obstet Gynaecol Res 2007;33(4):452-456. DOI: 10.1111/j.1447-0756.2007.00573.x. Available from: https://pubmed.ncbi.nlm.nih.gov/17688611/.

14. Shafique U, Kazmi F, Rehana F. Vaginal isosorbide mononitrate and misoprostol for induction of cervical ripening prior to 1st trimester surgical evacuation of retained products of conception. Journal of Rawalpindi Medical College 2010;14(2):101-103. Available from: http:// journalrmc.com/index.php/JRMC/article/view/702.

15. Mousiolis A, Sindos M, Papantoniou N, et al. Can isosorbide mononitrate be useful in second trimester termination of pregnancies? Contraception 2013;88(1):41-44. DOI: 10.1016/j. contraception.2012.11.018. Available from: https://pubmed.ncbi.nlm. nih.gov/23290428/.

16. Osman I, MacKenzie F, Norrie J, et al. The "PRIM" study: a randomized comparison of prostaglandin E2 gel with the nitric oxide donor isosorbide mononitrate for cervical ripening before the induction of labor at term. Am JObstet Gynecol 2006;194(4):1012-1021.DOI: 10.1016/ j.ajog.2005.10.812. Available from: https://pubmed.ncbi.nlm.nih.gov/ $16580290 /$

17. Dave A, Nigam P, Maru L. Isosorbide mononitrate a nitric oxide donor:a study of its efficacy and safety as an agent for cervical ripening. J Obstet Gynaecol India 2015;65(3):162-166. DOI: 10.1007/s13224-014-0577-5. Available from: https://pubmed.ncbi.nlm.nih.gov/26085736/.

18. Sivakumar S, Nalina S, Fathima R, et al. Comparison of misoprostol and misoprostol with isosorbide mononitrate in second trimester termination of pregnancy. J Evid Based Med Healthcare 2016;3(63):3424-3429. DOI: 10.18410/jebmh/2016/737.

19. Dixi MS, Somalwar SA, Tathe GR. Effectiveness of isosorbide mononitrate vs prostaglandin E2 gel for cervical ripening: a study. J South Asian Feder Obstet Gynaecol 2019;11(5):288-291.DOI: 10.5005/ jp-journals-10006-1712. Available from: https://creativecommons.

20. Chhetri S, Pokharel H, Rijal R, et al. Assessment of the efficacy of different methods of second trimester abortion: an initial experience in eastern Nepal. JSAFOG 2015;7(3):182-184. DOI: 10.5005/ jp-journals-10006-1352. 